This is the peer reviewed version of the following article:

Vázquez, J. J., Panadero, S., \& Pascual, I. (2019). The particularly vulnerable situation of women living homeless in Madrid (Spain). The Spanish Journal of Psychology, 22, e52, 1-9, which has been published in final form at:

https://doi.org/10.1017/sjp.2019.58

This article may be used for non-commercial purposes in accordance with the Cambridge Core terms. 
Accepted version of the article:

Vázquez, J. J., Panadero, S., \& Pascual, I. (2019). The particularly vulnerable situation of women living homeless in Madrid (Spain). The Spanish Journal of Psychology, 22, e52, 1-9. doi:10.1017/sjp.2019.58

Copyright: (C) Cambridge Core.

\title{
THE PARTICULARLY VULNERABLE SITUATION OF WOMEN LIVING HOMELESS IN MADRID (SPAIN)
}

\author{
José Juan Vázquez Cabrera ${ }^{1}$, Sonia Panadero Herrero ${ }^{2}$, and Isabel Pascual ${ }^{1}$
}

1. Universidad de Alcalá (Spain)

2. Universidad Complutense (Spain)

Corresponding author: José Juan Vázquez, Ph.D. Universidad de Alcalá. Departamento de Psicología Social. Aulario María de Guzmán, Calle San Cirilo, s/n, 28801 Alcalá de Henares (Spain). E-mail: jj.vazquez@uah.es

Funding statement: This work was supported by the Agencia Estatal de Investigación of the Ministerio de Economía, Industria y Competitividad of Spain under Grant FEM201675317-R.

Conflicts of interest: None of the authors have any conflict of interest. 


\begin{abstract}
People in homeless situation are one of the major embodiments of the phenomenon of social exclusion, and women living homeless are considered a particularly vulnerable group. This paper examines different variables that may affect the situation of vulnerability experienced by women living homeless in Madrid (Spain). The study was carried out using data obtained from a representative sample of homeless men in Madrid $(n=158)$ and a sample of homeless women in Madrid of a similar size $(n=138)$. The information was gathered using a structured interview in shelters or other facilities for people in a homeless situation, on the street and in other places not initially designed for sleeping. The results show that woman living homeless are highly vulnerable compared to the domiciled population and, in some respects, to homeless men as well, especially in the number of times homeless $\left(\chi^{2}=10.314 ; p<.01\right)$, in the time working with a contract and/or self-employed $(\mathrm{t}=5.754 ; \mathrm{p}<.001)$, and in the use of sedatives $\left(\chi^{2}=14.741 ; p<.001\right)$. It is however noted that homeless women show in some aspects greater strengths than homeless men. Such strengths could serve as a supporting point for their social inclusion processes. The analysis of issues that differentiate women in a homeless situation from their male counterparts could be useful for developing public policies and care resources adapted to the specific characteristics and needs of women living homeless.
\end{abstract}

Keywords: homelessness, social exclusion, women. 


\section{Introduction}

In developed societies, people in homeless situation are one of the most obvious embodiments of the phenomenon of social exclusion (Vázquez, Panadero, Martín, \& DíazPescador, 2015). Homeless people not only live in extreme poverty, but also suffer from high levels of family and social disengagement, and have great difficulty in achieving social/employment reintegration, and significant health problems (Vázquez, Panadero \& Zúñiga, 2017a, 2017b, 2018). Women living homeless are in a particularly vulnerable subgroup among people in a homeless situation (Arangua, Andersen, \& Gelberg, 2005; Ryan et al., 2009), with characteristics, needs and life trajectories that are different from those of homeless men (Vázquez et al., 2017a). Given that women living homeless in shelters or in the street account for a relatively small percentage of the population of homeless people in Spain (Muñoz, Vázquez, \& Vázquez, 2004; Panadero \& Vázquez, 2016; Vázquez et al., 2015), hardly any research with a gender perspective focused specifically on them has been carried out.

Beyond Spain's borders, various studies have examined the differences between homeless women and men. For example, several studies report that homeless women have a lower average age than homeless men, are more likely to be more accompanied by small children, and rarely sleep in the street (Marsapt, 2000; North \& Smith, 1993). Various authors (Christensen \& Vinther, 2005; Marsapt, 2000; North \& Smith, 1993; Piliavin, Wright, Mare, \& Westerfelt, 1996; Zlotnick, Robertson, \& Lahiff, 1999) have pointed out that periods of homelessness are longer for men than women, while Christensen and Vinther (2005) report that men experience considerably more episodes of homelessness than women. In Madrid, 28\% of the homeless people had been homeless between two and five times, and 14\% more than five times (Roca, Panadero, Rodríguez, Martín, \& Vázquez, 2019). Unfortunately, suffering from multiple episodes of homelessness after having gained access to independent housing (the revolving door to homelessness) is an issue that is rarely addressed in the scientific literature (Ringwalt, Greene, Robertson, \& McPheeters, 1998), especially as regards homeless women.

Different circumstances that affect homeless people (e.g. poor education, difficult access to the labour market, state of health, excessive consumption of psychoactive substances, poor social support, etc.) may be vulnerability factors that potentially lead to them becoming and remaining homeless, and have different effects according to gender (Roca et al., 2019). In relation to these issues, various studies carried out outside Spain show that compared to homeless men, homeless women have a higher level of education (e.g. North \& Smith, 1993), have had more unstable and lower-quality jobs during their lives (e.g. O'Grady \& Gaetz, 2004, Okamoto, 2007), have a worse state of health (e.g. Arangua et al., 2005; Wenzel, Leake, \& Gelberg, 2000) and are forced to overcome more barriers in order to access medical care (e.g. Gelberg, Browner, Lejano, \& Arangua, 2004; Lewis, Andersen, \& Gelberg, 2003), although they have fewer problems arising from excessive alcohol consumption (e.g. Christensen \& Vinther, 2005; Suarez, Berrios, Bonilla, \& Vázquez, 2018; North \& Smith, 1993; Vázquez, Berrios, Bonilla, \& Suarez, 2019). Furthermore, several studies have shown that there are no relevant differences among homeless people according to gender in terms of excessive drug use (e.g. Arangua et al., 2005; Christensen \& Vinther, 2005; Robertson, Zlotnick, \& Westerfelt, 1997) or reporting feelings of loneliness (e.g. Rokach, 2005).

In Madrid (Spain), various studies have found that the educational level of homeless people is lower than that of the general population (e.g. Leonori et al., 2000; Muñoz, et al., 2004; Panadero \& Vázquez, 2016), and they have extreme difficulty in accessing the labour market (e.g. Muñoz et al., 2004; Panadero \& Vázquez, 2016). The health of homeless people is also considerably worse than that of the general population (e.g. Leonori et al., 2000; Muñoz et al., 2004; Panadero \& Vázquez, 2016). While homeless people in Madrid tend to present very 
high levels of alcohol consumption (Panadero, Vázquez, \& Martín, 2017), drug consumption does not appear to be as widespread in this group, despite being higher than the average for the Spanish population (Panadero \& Vázquez, 2016). In addition, homeless people in Madrid have also been found to have little social support (e.g. Muñoz et al., 2004; Panadero, Guillén, \& Vázquez, 2015; Panadero \& Vázquez, 2016).

Although government agencies and service providers tend to consider women living homeless as being particularly vulnerable (Panadero \& Vázquez, 2016), the specific scientific literature in Spain on women in a homeless situation is very limited, and no thorough research that specifically addresses the differences between homeless women and men has been published. This study aims to examine the existence of possible vulnerabilities in terms of characteristics, situation and needs, of women living homeless in Madrid (Spain) in regard to the domiciled population and according to gender.

\section{Participants}

\section{Method}

The study was carried out in Madrid (Spain) with a representative sample of homeless men $(n=158)$ and a sample of homeless women of a similar size $(n=138)$. Participants were all adults with enough knowledge of Spanish to understand the questions, who had spent the night before the interview in a shelter or other facility for homeless people, on the street or in other places not initially designed for sleeping: abandoned buildings, basements, metro stations, etc. The basic socio-demographic characteristics of the two samples and the usual locations where the interviewees spend the night are shown in Table 1.

Table 1. Differences in Socio-demographic Characteristics and Places for Overnight Stays by Women and Men Living Homeless in Madrid

\begin{tabular}{lccc}
\hline & $\begin{array}{c}\text { Women } \\
(\mathbf{n = 1 3 8})\end{array}$ & $\begin{array}{c}\text { Men } \\
(\mathbf{n}=\mathbf{1 5 8})\end{array}$ & $\boldsymbol{t} / \chi^{\mathbf{2}}$ \\
\hline Age (M years, SD) & $45.52(11.38)$ & $47.08(12.30)$ & 1.123 \\
& & & 0.538 \\
Nationality & $69.6 \%$ & $73.4 \%$ & \\
$\quad$ Spanish & $30.4 \%$ & $26.6 \%$ & \\
$\quad$ Foreign & & & \\
& & & 6.925 \\
Marital status & $54.4 \%$ & $59.4 \%$ & \\
$\quad$ Single & $3.8 \%$ & $6.5 \%$ & \\
$\quad$ Married & $29.1 \%$ & $20.3 \%$ & \\
$\quad$ Legally separated or divorced & $10.1 \%$ & $8.7 \%$ & \\
$\quad$ Separated de facto without legal procedures & $1.9 \%$ & $5.1 \%$ & \\
$\quad$ Widowed & $0.6 \%$ & $0.0 \%$ & \\
$\quad$ Other & & & \\
& $56.2 \%$ & $58.0 \%$ & 0.92 \\
Has children & $1.23(1.93)$ & $1.21(1.84)$ & -0.073 \\
$\quad$ Number of children $(M$ children, SD) & & & \\
& & & \\
In the past month s/he has slept... & $11.7 \%$ & $27.8 \%$ & $11.840^{* *}$ \\
$\quad$ In the street & $81.9 \%$ & $69.6 \%$ & $5.963 *$ \\
\hline In a hostel
\end{tabular}

Note. ${ }^{*} p \leq .05 . * * p \leq .01 . * * * p \leq .001$. 
As shown in Table 1, both the homeless women and the homeless men had an average age of around 46 years, and most of them were Spanish, single or separated/divorced. More than half had children, with an average of 1.2 offspring. No statistically significant differences were observed between women and men in terms of age, marital status, nationality or having children. The interviewees who had been mothers had a mean of 2.18 children $(S D=1.300)$, and their first child had been born when the mother's mean age was 21.8 years old $(S D=5.300)$. Differences in the place where women and men stayed overnight during the month prior to the interview were observed, as a larger percentage of women had slept in a shelter and a smaller percentage had spent the night in the street.

\section{Procedure}

The sample size of men in a homeless situation was determined beforehand, based on the available data for the total number of people living homeless in Madrid (Panadero \& Vázquez, 2016). We designed a strategy for random sampling in the street and in all housing resources for homeless men in Madrid: The sample selection in the street was carried out randomly and proportionally, based on the number of homeless men sleeping on the streets of Madrid; and we selected a specific number of participants proportionately and randomly in each service, according to their capacity. Given the relatively small number of women living homeless in the street in or in shelters in Madrid, in order to access a sample of a similar size to the sample of homeless men we interviewed all the women who agreed to participate, both in care services for homeless women and on the street. The time period of conducting the interviews was eight months for the homeless men (November 2011 - June 2012) and one year for the homeless women (November 2014 - November 2015).

The participants were asked for their informed consent after receiving an explanation of the purpose of the research and the treatment that the data would receive, and they were assured that their anonymity would be respected. In view of the results obtained in previous studies (Muñoz et al., 2004; Panadero \& Vázquez, 2016), we assumed that a relatively high number of respondents could have a low or very low level of education, and that the number of people living homeless in Madrid of foreign origin - with potential difficulties with understanding the language - would be relatively high. As a result, a structured interview was used to gather information, which enabled us to circumvent the possible problems arising from the interviewees' difficulties with reading and/or understanding. We used a structured interview with the choice of answers to the questions fixed (close-ended) in advance, though a few openended questions was also included which required very short answers. The interviews lasted between 45 and 80 minutes.

The database was developed and processed using the SPSS statistical analysis and data management system. When making comparisons, the Chi square $(\chi 2)$ statistic was used for nominal variables, and the "Student $t$ " test for independent samples was used for continuous variables. 


\section{Results}

Table 2. Differences in Time Spent Homeless, Number of Episodes of Homelessness and Age at which They Became Homeless for the First Time between Women and Men Living Homeless in Madrid.

\begin{tabular}{|c|c|c|c|}
\hline & $\begin{array}{l}\text { Women } \\
(n=138)\end{array}$ & $\begin{array}{c}\text { Men } \\
(n=158)\end{array}$ & $t / \chi^{2}$ \\
\hline Number of times homeless during their life & & & $10.314 * *$ \\
\hline Once & $42.0 \%$ & $55.9 \%$ & \\
\hline 1 to 5 times & $27.5 \%$ & $28.9 \%$ & \\
\hline More than 5 times & $30.5 \%$ & $15.1 \%$ & \\
\hline Age when they become homeless ( $M$ years, $S D$ ) & $35.33(14.96)$ & $36.01(13.54)$ & 0.404 \\
\hline Time spent homeless ( $M$ month, $S D)$ & $75.26(90.54)$ & $82.91(99.24)$ & 0.669 \\
\hline
\end{tabular}

Note. ${ }^{*} p \leq .05 .{ }^{* *} p \leq .01 .{ }^{* * *} p \leq .001$.

Table 2 shows that there are no statistically significant differences between women and men in terms of the age when they became homeless for the first time - which occurred at an average age of 35-36 years old in both cases, nor in the average time spent homeless, which was in on average more than six years both cases. However, differences were found in the number of episodes of homelessness during the interviewees' lives, with women drifting in and out of homelessness more frequently: $56 \%$ of the homeless men had been homeless once, compared to $42 \%$ of the homeless women, while $30 \%$ of the homeless women had succumbed to and overcome homelessness more than 5 times, compared to $15 \%$ of the homeless men.

Table 3. Differences in Level of Education, Employment and Income between Women and Men Living Homeless in Madrid

\begin{tabular}{|c|c|c|c|}
\hline & $\begin{array}{c}\text { Women } \\
(n=138)\end{array}$ & $\begin{array}{c}\text { Men } \\
(n=158)\end{array}$ & $t / \chi^{2}$ \\
\hline Level of education & & & $19.167^{* *}$ \\
\hline No education & $9.4 \%$ & $6.5 \%$ & \\
\hline Incomplete primary education & $13.0 \%$ & $32.9 \%$ & \\
\hline Primary education (up to 14 years old) & $32.6 \%$ & $32.9 \%$ & \\
\hline Secondary (up to 18 years old) & $27.5 \%$ & $16.1 \%$ & \\
\hline Higher university studies & $17.4 \%$ & $11.6 \%$ & \\
\hline $\begin{array}{l}\text { Time working with a contract and/or self-employed } \\
(M \text { months, } D T)\end{array}$ & $\begin{array}{c}83.07 \\
(109.20)\end{array}$ & $\begin{array}{c}164.43 \\
(129.47)\end{array}$ & $5.754 * * *$ \\
\hline \multicolumn{4}{|l|}{ Financial income in the month prior to the interview } \\
\hline Begging & $19.6 \%$ & $13.3 \%$ & 2.134 \\
\hline Basic guaranteed income & $17.4 \%$ & $20.3 \%$ & 0.393 \\
\hline Wages & $9.4 \%$ & $8.2 \%$ & 0.131 \\
\hline Criminal activities & $4.4 \%$ & $2.5 \%$ & 0.808 \\
\hline Permanent disability pension & $4.3 \%$ & $3.8 \%$ & 0.057 \\
\hline Prostitution & $2.9 \%$ & $1.3 \%$ & 1.026 \\
\hline Retirement pension & $2.2 \%$ & $4.4 \%$ & 1.149 \\
\hline Marginal activity & $2.9 \%$ & $5.1 \%$ & 0.864 \\
\hline Widowhood pension & $0.7 \%$ & $0.0 \%$ & 1.149 \\
\hline $\begin{array}{l}\text { Total income in the month prior to the interview from } \\
\text { all those sources }(M \text { euros, } S D)\end{array}$ & $\begin{array}{c}223.58 \\
(287.63)\end{array}$ & $\begin{array}{c}218.54 \\
(198.86)\end{array}$ & -0.170 \\
\hline
\end{tabular}

Note. ${ }^{*} p \leq .05 .{ }^{* *} p \leq .01 .{ }^{* * *} p \leq .001$. 
As can be seen from Table 3, there are differences between the women and men in terms of their level of education: Although the percentage of people with no education was similar in both groups, a larger percentage of males had not completed primary education, while more women had completed secondary or university education. However, despite the higher educational level among the women, they had had access to regulated employment for only half the time as the men had - an average of 7 years for the women, and 14 years for the men. No statistically significant differences according to gender were observed in terms of the main sources of income or the amount of money received by the interviewees, which was around 220 Euros per month on average. In both cases, the main sources of income were begging and the basic guaranteed income, while less than $10 \%$ earned income from some sort of employment.

Table 4. Differences in Health and Consumption of Psychoactive Substances between Women and Men Living Homeless in Madrid

\begin{tabular}{|c|c|c|c|}
\hline & $\begin{array}{l}\text { Women } \\
(n=138)\end{array}$ & $\begin{array}{c}\text { Men } \\
(n=158)\end{array}$ & $t / \chi^{2(a)}$ \\
\hline $\begin{array}{l}\text { Has been diagnosed with a serious or chronic illness by a } \\
\text { doctor }\end{array}$ & $53.7 \%$ & $40.9 \%$ & $4.727^{*}$ \\
\hline Has a disability or handicap (physical, sensory, mental) & $36.8 \%$ & $37.6 \%$ & 0.017 \\
\hline Has an officially recognised disability & $70.0 \%{ }^{(2)}$ & $61.0 \%{ }^{(a)}$ & 0.962 \\
\hline \multicolumn{4}{|l|}{ Has used cocaine } \\
\hline At some point in his/her life & $41.3 \%$ & $40.4 \%$ & 0.026 \\
\hline In the last 6 months & $11.6 \%$ & $7.7 \%$ & 1.253 \\
\hline \multicolumn{4}{|l|}{ Has used heroin } \\
\hline At some point in his/her life & $26.1 \%$ & $23.9 \%$ & 0.912 \\
\hline In the last 6 months & $6.5 \%$ & $3.2 \%$ & 1.743 \\
\hline \multicolumn{4}{|l|}{ Has used cannabis } \\
\hline At some point in his/her life & $39.9 \%$ & $60.3 \%$ & $12.193 * * *$ \\
\hline In the last 6 months & $10.9 \%$ & $20.5 \%$ & $5.070 *$ \\
\hline \multicolumn{4}{|l|}{ Has used sedatives } \\
\hline At some point in his/her life & $58.7 \%$ & $41.7 \%$ & $8.494 * *$ \\
\hline In the last 6 months & $51.4 \%$ & $29.5 \%$ & $14.741 * * *$ \\
\hline Frequency of consumption of alcohol & & & $37.743 * * *$ \\
\hline Never & $63.8 \%$ & $29.2 \%$ & \\
\hline One or fewer times a month & $11.6 \%$ & $14.3 \%$ & \\
\hline $2-4$ times a month & $7.2 \%$ & $13.0 \%$ & \\
\hline 2-3 times a week & $5.1 \%$ & $12.3 \%$ & \\
\hline 4 or more times per week & $12.3 \%$ & $31.2 \%$ & \\
\hline Usual consumption of alcohol in a single day ( $M$ glasses, $S D$ ) & $\begin{array}{c}1.46 \\
(3.215)\end{array}$ & $\begin{array}{c}6.09 \\
(12.049)\end{array}$ & $4.457 * * *$ \\
\hline
\end{tabular}

Note. ${ }^{(a)} \%$ of those with a disability

$* p \leq .05 . * * p \leq .01 .{ }^{* * *} p \leq .001$. 
As can be seen in Table 4, more women than men had been diagnosed with a serious or chronic illness, although there were no statistically significant differences according to gender in terms of the perception of having a disability or the official recognition thereof. The most frequently consumed drugs by people living homeless in Madrid were cannabis, cocaine and particularly sedatives, with some differences observed in this respect according to the gender of the interviewees. In specific terms, the women reported a greater consumption of sedatives, both throughout their lives and in the six months prior to the interview, while the men reported a greater consumption of cannabis, both throughout their life and in the previous six months. No statistically significant differences were observed according to gender in terms of use of heroin and cocaine. The women reported a lower frequency of alcohol consumption, which is particularly striking among those that never consume alcohol (64\% women vs. $29 \%$ men) and those that regularly consume it four or more times per week ( $12 \%$ women vs. $31 \%$ men). The women also had a much lower average level of daily alcohol consumption than the men.

Table 5. Differences in Social Support between Women and Men Living Homeless in Madrid

\begin{tabular}{|c|c|c|c|}
\hline & $\begin{array}{c}\text { Women } \\
(n=138)\end{array}$ & $\begin{array}{c}\text { Men } \\
(n=158)\end{array}$ & $\chi^{2}$ \\
\hline Has family & $87.3 \%$ & $87.7 \%$ & 0.012 \\
\hline Frequency of contact with his/her family & & & $8.428^{*}$ \\
\hline Never or less than once a month & $70.2 \%$ & $78.0 \%$ & \\
\hline Monthly & $9.1 \%$ & $13.5 \%$ & \\
\hline At least once a week & $20.7 \%$ & $8.5 \%$ & \\
\hline $\begin{array}{l}\text { Level of satisfaction with his/her relationship with } \\
\text { his/her family }\end{array}$ & & & 1.464 \\
\hline None or little & $53.7 \%$ & $61.2 \%$ & \\
\hline Quite or a lot & $46.3 \%$ & $38.8 \%$ & \\
\hline Has a partner & $39.9 \%$ & $17.1 \%$ & $19.063 * * *$ \\
\hline Frequency of contact with his/her partner & & & 4.679 \\
\hline Never or less than once a month & $7.3 \%$ & $20.7 \%$ & \\
\hline Monthly & $7.3 \%$ & $13.8 \%$ & \\
\hline At least once a week & $85.5 \%$ & $65.5 \%$ & \\
\hline Satisfaction with the relationship with his/her partner & & & $4.295^{*}$ \\
\hline None or little & $9.3 \%$ & $26.9 \%$ & \\
\hline Quite or a lot & $90.7 \%$ & $73.1 \%$ & \\
\hline The extent to which he/she fells alone or abandoned & & & 3.767 \\
\hline Not at all & $30.8 \%$ & $40.1 \%$ & \\
\hline Not much & $18.0 \%$ & $13.2 \%$ & \\
\hline Quite a lot & $19.5 \%$ & $21.1 \%$ & \\
\hline A lot & $31.6 \%$ & $25.7 \%$ & \\
\hline
\end{tabular}

Note. ${ }^{*} p \leq .05 .{ }^{* *} p \leq .01 .{ }^{* * *} p \leq .001$.

As can be seen in Table 5, no statistically significant differences were observed between women and men in terms of having a family, satisfaction with their family relationship, frequency of contact with their partner or the degree to which they felt alone or abandoned. However, the women said they were in contact with their family more often, and more of them had a partner, and they were more satisfied with their relationship than the men. 


\section{Discussion}

The women and men living homeless interviewed in Madrid did not differ significantly in terms of their main socio-demographic characteristics (age, nationality, marital status or number of children), although the women spent the night in shelters more often and slept less in the street often. These data are consistent with those reported by authors including Marsapt (2000) and North and Smith (1993). This situation tends to be related to greater vulnerability among women (Arangua et al., 2005; Ryan et al., 2009) and to the greater risk for them involved in spending the night in the street. The perception by the service providers of this greater vulnerability among women (Panadero \& Vázquez, 2016) seems to facilitate them being given priority access to care facilities and mechanisms.

Although studies carried out in various cultural contexts have found that men remain homeless for longer periods of time (Christensen \& Vinther, 2005; Marsapt, 2000; Piliavin et al., 1996; Zlotnick et al., 1999), no significant differences were observed in this study for remaining homeless according to gender. Despite having become homeless for the first time at relatively advanced ages (around 35 years on average), the homeless people in Madrid were chronically homeless to a significant extent regardless of gender, having been homeless for more than six years on average. However, contrary to the observations by other authors (Christensen \& Vinther, 2005), the phenomenon of the "revolving door to homelessness" seems to affect women to a greater extent in Madrid. Many circumstances may lead individuals to suffer from repeated episodes of homelessness after gaining access to independent housing, although issues related to health, excessive alcohol consumption and experiencing stressful life events appear to be particularly influential (Aubry, Klodawsky, \& Coulombe, 2012; Caton et al., 2005; Dworsky, Napolitano, \& Courtney, 2013; Greenberg \& Rosenheck, 2010; Kim, Kertesz, Horton, Tibbetts, \& Samet, 2006; Muñoz et al., 2004; Parker, 2010, Roca et al., 2019). There are various explanations for homeless women in Madrid becoming homeless on more occasions than men. According to the model proposed by Roca et al. (2019), suffering from serious or chronic illness (observed to a greater extent among women) has a negative effect on the "revolving door to homelessness," mediated by a negative perception of one's own health, which is in turn mediated by suffering from disability. Homeless women with a serious illness and/or a disability may have a limited ability to function, which leads to increased care needs and greater dependence on others (Parker, 2010). The low levels of social and family support available to homeless women hinder their access to the care required to deal with illness and disability, which increases their chances of repeatedly becoming homeless. Furthermore, idiosyncratic issues in Spanish culture could lead to women suffering from repeated episodes of homelessness, such as the perception of women as deserving of special help and protection (Panadero \& Vázquez, 2016). Accordingly, homeless women sometimes overcome homelessness by going to live with family or friends, establishing a relationship with a new partner, finding employment that provides accommodation, e.g. domestic service, gaining access to temporary income that allows them to pay for temporary accommodation, etc. However, in many cases, problems in their relationships with their relatives or friends, suffering from intimate partner violence or the breakdown of the relationship, the loss of employment or the loss of temporary income can make these women homeless once again.

The educational level of women living homeless is lower than that of the domiciled women, so that $38.9 \%$ of Spanish women between 25 and 64 years old had university studies (Instituto Nacional de Estadística [Statistics National Institute] INE, 2018) versus 17.4\% of the women living homeless. Although they have a higher level of education than homeless men, homeless women in Madrid face more difficulties in both gaining access to the labour market and keeping their job, to the extent where they have on average worked for half the time worked by the homeless men. It should be noted that more than half of the women living homeless 
interviewed in Madrid were mothers with an average of 2.2 children, this could have had an impact on the shortest time of work activity observed among women living homeless. This situation does not only seem to affect women living homeless in Spain, since studies carried out in various countries (e.g. USA, England, Japan, Canada) have also found that homeless women tend to have a higher level of education but have worse jobs, which more unstable and of poorer quality than those of homeless men (North \& Smith, 1993; O'Grady \& Gaetz, 2004; Okamoto, 2007). Among the homeless women, their academic background does not seem to be a factor protecting them from homelessness, and the serious difficulties they encounter in accessing the labour market can be a major handicap with a potential negative impact on becoming or remaining homeless and/or suffering from the revolving door to homelessness. Although differences between homeless women and men have been noted in terms of their academic background and employment history, once they have become homeless there are no differences according to gender in terms of sources of income or money they have access to. Among both homeless women and men in Madrid, the main sources of income were begging and the basic guaranteed income - although 10\% obtained income from employment, and they earned a monthly average of around 220 Euros, an insufficient amount to be able to live decently in the city of Madrid.

The percentage of women living homeless with disabilities $(36.8 \%)$ is four times higher than that of women in the Spanish general population (10.6\%) (INE, 2018) and, while $8.5 \%$ of women domiciled indicated having a "bad" or "very bad" health status, the women living homeless with serious or chronically illnesses diagnosed accounted for 53.7\% (INE, 2018). There are no significant differences according to gender among people living homeless in Madrid as regards disability. However, as observed in other countries (Arangua et al., 2005; Wenzel et al., 2000), homeless women in Madrid presented a poorer state of health, suffering from serious or chronic illness to a greater extent than homeless men. Authors including Gelberg et al. (2004) and Lewis et al. (2003) point out that homeless women also face more barriers to access medical care.

The psychoactive substances most commonly consumed by people living homeless in Madrid were cannabis, cocaine and above all, sedatives. It is noted that the consumption of psychoactive substances by women living homeless was much higher than that of Spanish domiciled women. Among the latter group $7.8 \%$ of women had used hypnosedatives, $2.5 \%$ cannabis and $0.4 \%$ cocaine during the year prior to the interview (Observatorio Español de las Drogas y las Adicciones [Spanish Observatory of Drugs and Addictions] OEDA, 2018). However, there are no gender differences among homeless people in Madrid for the use of heroin and cocaine, which is consistent with the reports in other contexts by Arangua et al., (2005), Christensen and Vinther (2005) and Robertson et al. (1997). Meanwhile, cannabis was consumed by a larger percentage of men among people living homeless in Madrid, while sedatives were consumed by women to a much greater extent, and more than half of them consumed these substances on a regular basis. The high consumption of sedatives among homeless women could be related to their poorer state of health, and a strong tendency among health professionals to prescribe this type of drug to homeless women (Panadero \& Vázquez, 2016). Finally, it should be noted that as in studies carried out in various cultural contexts (e.g. Christensen \& Vinther, 2005; Suarez et al., 2018; North \& Smith, 1993; Vázquez et al., 2019), homeless women in Madrid presented a lower rate of alcohol consumption than homeless men, with a high percentage of non-consumers and a relatively low percentage of habitual consumers of alcohol.

Suffering from chronic illnesses, disability and addiction problems can greatly hinder homeless people's ability to access the labour market, and prevent them from keeping a job, which has a very negative impact on their homelessness becoming chronic (Vázquez et al., 
2017a, 2018). Likewise, people in a homeless situation with serious illnesses, disabilities or addiction problems may have a limited general functional capacity, which would lead to an increase in their needs for care and greater dependence on other people (Parker, 2010). The low levels of social and family support available to people living homeless (Hwang et al., 2010) prevent them from accessing the care they need, which increases their likelihood of becoming homeless and suffering from the revolving door to homelessness to a greater extent.

A large percentage of people living homeless in Madrid reported feelings of loneliness or abandonment, although as in the results of the study by Rokach (2005), no differences in loneliness according to the gender of the interviewees were observed. Despite stereotypes to the contrary (Vázquez et al., 2017b), Bates and Toro (1999) point out that most homeless people are in regular contact with family. The vast majority of people living homeless in Madrid reported having a family, although they were dissatisfied with their family relationships to a large extent. The homeless women reported having particularly frequent contact with their relatives, which was at least weekly in a high percentage of cases. This regular contact with the family could be a facilitating factor for social inclusion processes, although in the opinion of Bates and Toro (1999), the homeless person's contact with their family may not always be positive. Meanwhile, $40 \%$ of the homeless women in Madrid said they had a partner. This percentage was that double that of homeless men with a partner. Although partner relationships among homeless women have sometimes been interpreted as a means of obtaining protection in hostile environments (e.g. Panadero \& Vázquez, 2016; Ryan et al., 2009), most of the women interviewed in Madrid (a much higher percentage than the men) were very satisfied with their relationship.

Tucker et al. (2009) point out that most women in a homeless situation reported having relationships that could be characterized as both "low risk" (e.g., involving individuals perceived as not drinking heavily, using drugs, or engaging in risky sex) and "high quality" (e.g., long-term, emotionally close, or supportive), although these relationships tended to be rather tenuous. Nyamathi, Leake, Keenan, and Gelberg (2000) observed that compared with those who have little or no support, homeless women whose support included substance nonusers reported better psychosocial profiles and somewhat greater use of health services. Since as Meadows-Oliver (2005) points out, homeless women feel estranged from sources of support, it would be important to strengthen their social networks and support their positive relationships, in order to improve their quality of life and reinforce their processes of inclusion. It would be positive to provide spaces and organise activities that facilitate the creation and development of "low risk" and "high quality" relationships (Tucker et al., 2009).

One of the main limitations of this study is that although it is based on a representative sample of homeless men in Madrid, it is impossible to guarantee the representativeness of the sample of homeless women. Furthermore, this is a cross-sectional study design, and as such caution must be exercised when trying to establish causal relationships. It should also be noted that we used a structured interview with closed response options and a few open-ended questions which required very short answers, but no qualitative data was collected. Finally, the study is limited to Madrid, Spain, which means that it is difficult to generalise the results to other contexts.

The results obtained show that women living homeless are highly vulnerable compared to the domiciled population and, in some respects (such as a greater "revolving door" to homelessness, lower working life, more serious or chronic illness, greater consumption of sedatives), to homeless men as well. Nevertheless it is observed that women living homeless show, in some aspects, greater strengths than homeless men (women have better academic training, lower consumption of cannabis and alcohol, greater contact with the family, more 
satisfying couple relationships...). Such strengths could be relevant points of support in their social inclusion processes. The analysis of issues that differentiate women in a homeless situation from their male counterparts could be useful for developing public policies and care resources adapted to the specific characteristics and needs of women living homeless.

\section{References}

Arangua, L., Andersen, R., \& Gelberg, L. (2005). The health circumstances of homeless women in the United States. International Journal of Mental Health, 34(2), 62-92. http://doi.org/10.1080/00207411.2005.11043398

Aubry, T., Klodawsky, F., \& Coulombe, D. (2012). Comparing the housing trajectories of different classes within a diverse homeless population. American Journal of Community Psychology, 49(1-2), 142-155. http://doi.org/10.1007/s10464-011-9444-z

Bates, D. S., \& Toro, P. (1999). Developing measures to assess social support among homeless and poor people. Journal of Community Psychology, 27, 137-156. http://doi.org/10.1002/(SICI)1520-6629(199903)27:2<137::AID-JCOP3>3.0.CO;2-B

Caton, C. L. M., Dominguez, B., Schanzer, B., Hasin, D. S., Shrout, P. E., Felix, A., ... Hsu, E. (2005). Risk factors for long-term homelessness: Findings from a longitudinal study of first-time homeless single adults. American Journal of Public Health, 95(10), 17531759. http://doi.org/10.2105/AJPH.2005.063321

Christensen, I., \& Vinther, H. (2005). Exit from homelessness. International Journal of Mental Health, 34, 3, 3-34. http://doi.org/10.1080/00207411.2005.11043403

Dworsky, A., Napolitano, L., \& Courtney, M. (2013). Homelessness during the transition from foster care to adulthood. American Journal of Public Health, 103(S2), S318S323. http://doi.org/10.2105/AJPH.2013.301455

Gelberg, L., Browner, C. H., Lejano, E., \& Arangua, L. (2004). Access to women's health care: A qualitative study of barriers perceived by homeless women. Women \& Health, 40(2), 87-100. http://doi.org/10.1300/J013v40n02 06

Greenberg, G. A., \& Rosenheck, R. A. (2010). Correlates of past homeless in the National Epidemiological Survey on Alcohol and Related Conditions. Administration and Policy in Mental Health and Mental Health Services Research, 37, 357-366. http://doi.org/10.1007/s10488-009-0243-x

Hwang, S. W., Ueng, J. J. M., Chiu, S., Kiss, A., Tolomiczenko, G., Cowan, L., ... Redelmeier, D. A. (2010). Universal health insurance and health care access for homeless persons. American Journal of Public Health, 100(8), 1454-1461. http://doi.org/10.2105/AJPH.2009.182022

Instituto Nacional de Estadística (INE) (2018). Mujeres y hombres en España [Women and men in Spain]. Retrieved from INE website http://www.ine.es/ss/Satellite?L=0\&c=INEPublicacion C\&cid $=1259924822888 \& p=1$ 254735110672\&pagename=ProductosYServicios\%2FPYSLayout\&param1=PYSDetal leGratuitas

Kim, T. W., Kertesz, S. G., Horton, N. J., Tibbetts, N., \& Samet, J. H. (2006). Episodic homelessness and health care utilization in a prospective cohort of HIV-infected persons with alcohol problems. BMC Health Services Research, 6(1), 19. http://doi.org/10.1186/1472-6963-6-19

Leonori, L., Muñoz, M., Vázquez, C., Vázquez, J. J., Bravo, M., Nuche, M., ... Horenbek, B. (2000). The mental health and social exclusion European network: A research activity report on European homeless citizens. European Psychologist, 5(3), 245-251. 
Lewis, J. H., Andersen, R. M., \& Gelberg, L. (2003). Health care for homeless women. Journal of General Internal Medicine, 18(11), 921-928. http://doi.org/10.1046/j.15251497.2003.20909.x

Marsapt, M. (2000). An advantage with limits. The lower risk for women of becoming homeless. Population, 12, 1-45.

Meadows-Oliver, M. (2005). Social support among homeless and housed mothers: An integrative review. Journal of Psychosocial Nursing and Mental Health Services, 43(2), 40-47. http://doi.org/10.3928/02793695-20050201-02

Muñoz, M, Vázquez, C., \& Vázquez, J. J. (2004). A comparison between homeless, domiciled and vulnerable populations in Madrid. Population, 59(1), 129-141.

North, C. S., \& Smith, E. M. (1993). A comparison of homeless men and women: Different populations, different needs. Community Mental Health Journal, 29(5), 423-431. http://doi.org/10.1007/BF00754410

Nyamathi, A., Leake, B., Keenan, C., \& Gelberg, L. (2000). Type of social support among homeless women: Its impact on psychosocial resources, health and health behaviors, and use of health services. Nursing Research, 49(6), 318-326.

http://doi.org/10.1097/00006199-200011000-00004

Observatorio Español de las Drogas y las Adicciones (OEDA) (2018). Alcohol, tabaco y drogas ilegales en España [Alcohol, tobacco and illegal drugs in Spain] Madrid, Spain: Ministerio de Sanidad, Consumo y Bienestar Social.

O'Grady, B., \& Gaetz, S. (2004). Homelessness, gender and subsistence: The case of Toronto street youth. Journal of Youth Studies, 7(4), 397-416. http://doi.org/10.1080/1367626042000315194

Okamoto, Y. (2007). A comparative study of homelessness in the United Kingdom and Japan. Journal of Social Issues, 63(3), 525-542. http://doi.org/10.1111/j.15404560.2007.00522.x

Panadero, S., \&Vázquez, J. J. (2016). En las fronteras de la ciudadanía. Situación de las personas sin hogar y en riesgo de exclusión social en Madrid [On the borders of citizenship. Situation of the homeless and at risk of social exclusion in Madrid]. Alcalá de Henares, Spain: Universidad de Alcalá. Retrieved from https://ebuah.uah.es/dspace/handle/10017/26604

Panadero, S., Guillén, A.I., \& Vázquez, J. J. (2015). Happiness in the street. Overall happiness among homeless people in Madrid (Spain). American Journal of Orthopsychiatry, 85(4), 324-330. http://doi.org/10.1037/ort0000080

Panadero, S., Vázquez, J. J., \& Martín, R. M. (2017). Alcohol, poverty and social exclusion: Alcohol consumption among the homeless and those at risk of social exclusion in Madrid. Adicciones, 29(1), 33-36. http://doi.org/10.20882/adicciones.830

Parker, D. (2010). Housing as an intervention on hospital use: Access among chronically homeless persons with disabilities. Journal of Urban Health, 87(6), 912-919. http://doi.org/10.1007/s11524-010-9504-y

Piliavin, I., Wright, B. R. E., Mare, R. D \& Westerfelt, A.. (1996). Exits from and returns to homelessness. Social Service Review, 70, 33-57. http://doi.org/10.1086/604164

Ringwalt, C. L., Greene, J. M., Robertson, M., \& McPheeters, M. (1998). The prevalence of homelessness among adolescents in the United States. American Journal of Public Health, 88(9), 1325-1329. http://doi.org/10.2105/AJPH.88.9.1325

Robertson, M. J., Zlotnick, C., \& Westerfelt, A. (1997). Drug use disorders and treatment contact among homeless adults in Alameda County, California. American Journal of Public Health, 87(2), 221-228. http://doi.org/10.2105/AJPH.87.2.221

Roca, P., Panadero, S., Rodríguez, S. I., Martín, R. M., \& Vázquez, J. J. (2019). Revolving door to homelessness. The influence of health, alcohol consumption and stressful life 
events on the number of episodes of homelessness. Anales de Psicología, 35(2), 175180. http://doi.org/10.6018/analesps.35.2.297741

Rokach, A. (2005). Private lives in public places: Loneliness of the homeless. Social Indicators Research, 72(1), 99-114. http://doi.org/10.1007/s11205-004-4590-4

Ryan, G. W., Stern, S. A., Hilton, L., Tucker, J. S., Kennedy, D. P., Golinelli, D., \& Wenzel, S. L. (2009). When, where, why and with whom homeless women engage in risky sexual behaviors: A framework for understanding complex and varied decisionmaking processes. Sex Roles, 61(7-8), 536-553. http://doi.org/10.1007/s11199-0099610-Z

Suarez, A., Berrios, A., Bonilla, E., \& Vázquez, J. J. (2018). Homeless people in Nicaragua: A point-in-time count in León. Journal of International Development, 30(1), 155-158. http://doi.org/10.1002/jid.3303

Tucker, J., Kennedy, D., Ryan, G., Wenzel, S., Golinelli, D., Zazzali, J., \& McCarty, C. (2009). Homeless women's personal networks: Implications for understanding risk behavior. Human organization, 68(2), 129-140. http://doi.org/10.17730/humo.68.2.m23375u1kn033518

Vázquez, J. J., Berrios, A., Bonilla, E., \& Suarez, A. C. (2019). Homeless people in León (Nicaragua). Conceptualising and measuring homelessness in a developing country. American Journal of Orthopsychiatry, 89(2), 296-303.

Vázquez, J. J., Panadero, S., Martín, R. M., \& Díaz-Pescador, V. (2015). Access to new information and communication technologies among homeless people in Madrid (Spain). Journal of Community Psychology, 43(3), 338-347. http://doi.org/10.1002/jcop.21682

Vázquez, J. J., Panadero, S., \& Zúñiga, C. (2017a). Actors, observers, and causal attributions of homelessness: Differences in attribution for the causes of homelessness among domiciled and homeless people in Madrid. American Journal of Orthopsychiatry, 87(1), 15-22. http://doi.org/10.1037/ort0000130

Vázquez, J. J., Panadero, S., \& Zúñiga, C. (2017b). Content and uniformity of stereotypes and meta-stereotypes of homeless people in Madrid (Spain). Community Psychology, 45(1), 128-137. http://doi.org/10.1002/jcop.21836

Vázquez, J. J., Panadero, S., \& Zúñiga, C. (2018). Attributions about homelessness in homeless and domiciled people in Madrid, Spain: «Why are they homeless people?». American Journal of Orthopsychiatry, 88(2), 236-247. http://doi.org/10.1037/ort0000246

Wenzel, S. L., Leake, B. D., \& Gelberg, L. (2000). Health of homeless women with recent experience of rape. Journal of General Internal Medicine, 15(4), 265-268. http://doi.org/10.1111/j.1525-1497.2000.04269.x

Zlotnick, C., Robertson, M., \& Lahiff, M. (1999). Getting off the streets: Economic resources and residential exits from homelessness. Journal of Community Psychology, 27, 209224. http://doi.org/10.1002/(SICI)1520-6629(199903)27:2<209::AIDJCOP8>3.0.CO;2-2 